\title{
Anonymity and confidentiality: Rural teenagers' concerns when accessing sexual health services
}

\author{
Ruth Garside, MA, BA, Research Fellow, Reproductive Health, School of Postgraduate Medicine and Health Sciences, \\ University of Exeter, Exeter, UK; Richard Ayres, MRCP, MRCGP, Medical Director/Research Fellow, Exeter and District \\ Community NHS Trust, Exeter, UK; Mike Owen, MB ChB, FFPHM, Director of Public Health, North and East Devon Health \\ Authority, UK; Virginia A H Pearson, MRCGP, FFPHM, Director of Public Health, Somerset Health Authority, UK; Judith \\ Roizen, PhD, Research Fellow, University of Exeter, Exeter, UK
}

Correspondence: Ruth Garside, Research Fellow, Reproductive Health, School of Postgraduate Medicine and Health Sciences, University of Exeter, Church Lane, Exeter, EX2 5SQ, UK

(Accepted $8^{\text {th }}$ June 2001)

The Journal of Family Planning and Reproductive Health Care 2002: 28(1): 23-26

\begin{abstract}
Context. While confidentiality is recognised as a key aspect of successful health services aimed at young people, most research has looked at the concerns of those in urban centres. This paper reports on qualitative and quantitative data collected from general practitioners (GPs) and young people in a rural health district.

Objective. To assess the concerns of rural teenagers regarding anonymity and confidentiality when accessing sexual health services.

Design. The views of teenagers about using health services for issues of sexual health were sought through an in-school survey of 311 Year 9 and 119 Year 11 students. In addition, 18 single-sex focus groups discussions were conducted in North and East Devon. All GPs in the district were asked to complete a questionnaire.

Results. These reveal that the particular concerns of young people from small communities are more to do with the difficulties of remaining anonymous, which are related to visibility and lack of privacy in small communities. These problems were more pervasive among rural young people than those concerns more usually reported about confidential consultations.
\end{abstract}

\section{Key message points}

- This article examines the concerns of rural young people about using local health services.

- It is well known that confidentiality is a key concern for young people who need sexual health services.

- Rural teenagers are more concerned about anonymity and the difficulties of conducting clinical consultations privately in small communities.

- Health professionals can address some of the specific concerns about the nature of confidentiality and privacy during consultations. However, other problems relating to the nature of small communities are more difficult to address.

\section{Introduction}

Currently women of any age, including under 16-year-olds, can access confidential contraceptive services through their own or another general practitioner (GP), and through community family planning clinics (FPCs). Where available, teenagers may also use specialist services such as Brook Advisory Centres or local teenage drop-ins. About $80 \%$ of all women now receive contraceptive services from a GP. ${ }^{1}$ In rural areas the percentage may be higher as the GP is often the only service available locally to meet the sexual health needs of teenagers, transport to other locations often being infrequent and costly.

In North and East Devon, the health district studied for this paper, there is only one FPC which opens every day, Monday to Saturday. Whilst this clinic is very well used by teenagers, ${ }^{2}$ its location renders it inaccessible to many of those in the district. The availability, cost and frequency of public transport are particularly important for teenagers. While there are also 14 satellite clinics in the district, including three at colleges for post-16s, one of the clinics is open twice a week and the rest on a weekly basis, so these are not ideal for teenagers' needs. A local survey of Year 9 and Year 11 rural school children showed that over onethird did not know the role of a FPC. They are unlikely to access a service they do not relate to their own needs. ${ }^{3}$

School nurses may also provide some sexual health services for teenagers including the provision of condoms, pregnancy tests and referrals to local GPs or FPCs for emergency and other methods of contraception. Where rural teenagers travel into school by bus, this has the advantage of serving a larger population than is possible in more remote areas. However, school nurses are only on site for part of the week and the service varies greatly between schools. It may be particularly restricted where there is no sixth form. In addition, fear of parental disapproval may prevent school nurses from widely publicising services they do offer. ${ }^{4}$

Given that current service provision in the district relies heavily on the ability of general practices to meet the needs of sexually active teenagers, it is important to understand the ways in which they can and cannot respond to those needs. A key issue in providing appropriate sexual health services for teenagers is confidentiality. Allen ${ }^{5}$ described confidentiality as 'the single most important factor in designing services for young people'. Since the Fraser ruling in $1985,{ }^{6}$ doctors have followed guidelines enabling them to provide confidential sexual health care to under $16 \mathrm{~s}$, providing they are judged in need of this care and mature enough to understand their treatment. However, confidentiality for teenagers involves more than simply having faith that a health professional will not report an encounter to parents, relatives or teachers, although this may still be a concern for a minority. Other issues may be equally or even more important. These include problems of privacy, anonymity and visibility in small communities. 
Taken together, these concerns combine to give a more complex view of teenagers' fears relating to confidentiality and using sexual health services. Many studies of services have concentrated on the issues for teenagers in urban areas. ${ }^{5,7}$ In rural areas, problems related to confidentiality and anonymity may be even more acute. Rural teenagers already suffer from a restricted range of services accessible to them; this paper will discuss the psychological barriers which may prevent them from using those services closer to home.

\section{Method}

Quantitative and qualitative data have been triangulated to provide a robust picture of services and attitudes in the district. Data used in this paper were collected through:

(1) A self-administered questionnaire undertaken in school by all Year $11(\mathrm{n}=119)$ and Year $9(\mathrm{n}=152)$ pupils in a rural Devon secondary school in May and July 1999. All Year 9 pupils in July 2000 also completed the questionnaire $(\mathrm{n}=159)$. Year 9 results were combined. All pupils present on the day completed the questionnaire, which asked about their use of the GP, attitudes towards health professionals, use of sexual health services, knowledge of contraception and personal sexual activity. Data presented here relate to issues of anonymity and confidentiality. Other data have been reported elsewhere. ${ }^{3,8}$

(2) Eighteen focus group discussions were conducted in five locations around North and East Devon. Groups were single sex and contained between four and nine either under or over 16-year-olds. They were recruited with the help of youth workers and college nurses, and met in a variety of locations either in the evening or during school/college hours, depending on the circumstances. All participants were offered a high street gift voucher worth $£ 5$ to encourage participation. Participants were assured of confidentiality. All the sessions were tape-recorded and transcribed at the Institute of Population Studies, University of Exeter. All names have been changed here and locations have been given pseudonyms to ensure confidentiality and anonymity. Using a series of scenarios relating to different aspects of sex [such as wanting to obtain free condoms or thinking they may have a sexually transmitted infection (STI)], the focus groups were asked where they would suggest a friend went or who they thought they should talk to in those situations. Their answers were then used to explore what services were known about and how they were regarded.

(3) A postal, self-administered questionnaire was distributed to all 321 GPs at the 78 general practices in North and East Devon in January 1999. A total of 235 GPs from 67 practices returned questionnaires, giving a response rate of $73.2 \%$. The questionnaire asked about GPs' experience of, and attitudes towards, treating under $16 \mathrm{~s}$ for sexual health issues, and their opinion of the Fraser ${ }^{6}$ ruling.

\section{Results}

Teenagers' perceptions of anonymity and confidentiality The school-based survey asked if respondents agreed, disagreed, were neutral or didn't know in relation to a series of statements. When shown 'I would trust my doctor to keep what I say confidential', 72.9\% of pupils said that they agreed. However, this doesn't mean that teenagers were sure that their visit would be totally confidential in reality.

Being seen. For rural teenagers, issues of confidentiality and anonymity permeate every stage of the consultation going into the doctors, in the waiting room, going to the chemist, and future consultations. Foremost in many of the focus groups was the fear of being seen attending a health service and that their visit would be reported to their parents, through concern or gossip. While the doctor may be trusted to keep confidence, there are many other individuals with whom they have a connection and whom have the ability to expose them. Young people feel vulnerable due to their visibility in small communities. Networks of friends, relatives and acquaintances are wide, and teenagers assume that they will be seen by someone they know and that their actions will be scrutinised and shared.

"You've got to get a prescription and you've got to go to the chemist."

"Yeah and there's always like a friend, put it that way, that works there...."

"If it's like a local pharmacy and people know you, gossip can get around."

(Greenham girls 16+)

"If you are worrying about it, like about maybe being pregnant or something, the last thing you need to worry about is like your mum's best friend seeing you walking in the doctor's."

(Greenham girls 16+)

"One of my old friend's mum is one of the receptionists at Pinkham surgery and also my mum's friend is another receptionist, and our old next door neighbour's a receptionist, it's like a whole, a whole history... I found it really hard when I went in there to tell them why I was there, because I know them, from like three out of the four receptionists I knew."

(Pinkham girls 16+)

This last quote shows how inter-connected many teenagers feel in their communities. Whilst this can offer a sense of belonging, it also makes privacy incredibly difficult to achieve.

Teenagers are also very aware of small town 'rumour mills'. Some may have relatives whose own jobs put them in a position to hear what's going on in the town or village, including about their own children:

$$
\begin{aligned}
& \text { "Cos your mum works in the shop and she'd pick that } \\
& \text { up really easily." }
\end{aligned}
$$

$$
\text { (Greyville girls <16) }
$$

The power of these networks can seem all encompassing. For these girls, the sense of being under scrutiny achieves almost mythic proportions, with the village eyes seemingly all seeing and beyond her control:

"I know it's completely confidential but like if you are under 16 then your parents will find out any information, even if you just go."

(Greenham girls <16)

"You go in there [doctor's] and you'll see loads of your friends in there and you'll think 'Oh God, it's going to go all around the village, my mum's going to find out'.",

(Brownton girls <16)

\footnotetext{
"I mean, this is Greyville, it might be that the doctors are not allowed to say anything, but you go in them and the next day it's all round Greyville."
} 
"Yeah, everybody knows."

"It's such a small place."

"Something happens between two people and the next day everyone knows about it...it's just like, in the air."

(Greyville girls <16)

The final quote shows that the speakers are fully aware of doctors' duty of confidentiality, but this is a minor point of security compared to the power they assign to gossip in their town.

Health professionals and family friends. People in the health professions are relatively high profile in small communities, known to many people and also holding information about many. A surprising number of focus group participants identified a personal relationship with a doctor, nurse, or receptionist, either because their parents knew them, or because they knew the children of the health professional. Teenagers were unclear that professional confidentiality would extend into personal relationships:

"I couldn't trust the school nurse because she's the mum of one of my football team."

(Blueham boys <16)

"My doctor is sort of like my dad's best mate and I'd be
embarrassed like just say one night ... it slipped out."

(Greyville girls <16)

Rather than fearing that a health professional would purposefully contact their parents and break their confidence, teenagers felt threatened by 'off-duty' slip-ups in personal relationships.

Future visits. In addition to feeling threatened by professionals' personal relationships, teenagers were aware that a sexual health visit might resurface in future consultations. They may get away with a secret visit at the time, but it may return to them later. In the survey of school children, over one-half of Year 9 and two-thirds of Year 11 pupils had attended at least one doctor's appointment on their own. Girls were more likely than boys to have done so (Table 1). However, parents might still be present at some of their consultations. Information about sex could be relayed either through a careless positioning of the computer screen which displays their records, or insensitive questioning. Some FGD participants had first-hand experience of this happening and such tales add to the fear of others:

"They've got this screen, it's got all your records on it, you can see all the records. If your mum's sitting there she can see all the records."

(Greenham girls 16+)

"It's like 'Verucca, verucca, bad ear, bad foot, bad throat, morning after pill, bad throat'."

(Greyville girls <16)

"[Mum] came in and they took me into the examination room and he said 'Oh do you take any regular medication?'. And my mum was sat there, and she didn't know so I said 'No'. And he goes 'Are you on the pill?' and I'm like 'Shhhh!'”

(Greenham girls 16+)

Such stories are perceived as a threat to confidential advice and add to some young people's reticence about attending the GP.

Table 1 Have you ever been to see your doctor on your own?

\begin{tabular}{llllllllll}
\hline & \multicolumn{3}{c}{ Year 9 $(\mathrm{n}=311)$} & & \multicolumn{3}{c}{ Year 11 $(\mathrm{n}=119)$} & \\
\cline { 2 - 3 } & All & Girls & Boys & & All & Girls & Boys & \multirow{2}{*}{ All } \\
\hline No & 51.8 & 47.0 & 57.2 & & 31.9 & 30.3 & 35.8 & 46.4 \\
Yes - once & 19.6 & 19.9 & 19.3 & & 20.2 & 21.2 & 17.0 & 19.7 \\
Yes - more than once & 28.6 & 33.1 & 23.4 & & 47.9 & 48.5 & 47.2 & 33.9 \\
\hline
\end{tabular}

For Year 9 by sex, Chi square $=4.121, \mathrm{DF}=2, \mathrm{p}=0.127$

For Year 11 by sex, Chi square $=0.55875, \mathrm{DF}=2, \mathrm{p}=0.756$

For boys and girls by year, Chi square $=16.140, \mathrm{DF}=2, \mathrm{p}=0.000^{*}$.

All values are percentages.

\section{Doctors' attitudes to anonymity and confidentiality}

On the whole, health professionals were clear about the obligation to provide a confidential service, which was clarified by the Fraser ${ }^{6}$ ruling. In the survey of GPs, over $90 \%$ agreed that they owed the same duty of confidentiality to under $16 \mathrm{~s}$ as to their other patients. ${ }^{9}$ The attitudes of the doctors, however, are complicated by their discomfort in treating this group for sexual health matters.

Two separate questions were asked about parental knowledge; 'Where I see girls who are under 16 and having a sexual relationship, I would prefer that their parents knew they had sought my advice' and 'Where I see girls who are under 16 and having a sexual relationship, I would prefer that their parents knew they had sought contraception from me'. GPs were asked to indicate their level of agreement with each statement using a five-point Likert scale. The majority of GPs would prefer parents to know they had been consulted by an under 16 , with $70.2 \%$ agreeing they would prefer it if it were known that they had been consulted for advice and $76.3 \%$ agreeing that they would prefer it if it were known that they had been consulted to supply contraception (Table 2).

Table 2 GPs who would prefer that parents knew that they had been consulted by an under 16-year-old for advice or contraception

\begin{tabular}{lcc}
\hline & Sought advice & Sought contraception \\
\hline Strongly agree & 9.9 & 12.9 \\
Agree & 60.3 & 63.4 \\
Neither agree nor disagree & 20.7 & 15.5 \\
Disagree & 7.3 & 6.9 \\
Strongly disagree & 1.7 & 1.3 \\
\hline
\end{tabular}

Missing data $(n=3)$ excluded. Column totals may not equal 100 due to rounding. All values are percentages.

These attitudes are in line with the Fraser ${ }^{6}$ ruling, which requires doctors to 'Emphasise the value of parental support and try to persuade the patient to inform, or let them inform, their parent's'. However, teenagers receiving this advice may find it inappropriate or intrusive:

"They say 'You should talk to your mum' but I'm like, well you don't know my mum!"

(Greyville girls <16)

Teenagers may also interpret this advice as patronising, or indicative that confidentiality may in fact be broken.

Respondents in the GP survey were also asked how comfortable they were giving sexual health advice to under 16 s and supplying them with contraception, again using a five-point Likert scale. Overall, GPs were much more 
comfortable giving advice than actually supplying contraception. Very few GPs $(3.4 \%)$ were uncomfortable giving advice, and slightly more (15.6\%) supplying contraception. However, nearly twice as many were comfortable giving advice compared to supplying contraception $(66.6 \%$ vs $37.2 \%)$ (Table 3$)$.

Table 3 How comfortable GPs feel giving sexual health advice and supplying contraception to under $16 \mathrm{~s}$

\begin{tabular}{lcc}
\hline & Giving advice & Supplying contraception \\
\hline Very comfortable & 17.0 & 5.6 \\
Comfortable & 49.6 & 31.6 \\
OK & 30.0 & 47.2 \\
Uncomfortable & 1.7 & 13.9 \\
Very uncomfortable & 1.7 & 1.7 \\
\hline
\end{tabular}

Missing data $(n=4, n=5)$ excluded. Column totals may not equal 100 due to rounding. All values are percentages.

Teenagers are sensitive to the attitudes of adults around them, and doctors' feelings of discomfort may be translated by young people as being disapproving:

"I think they don't like to think that people like our age and younger are actually having sex. I think that's the whole problem really with the doctor."

(Greyville girls 16+)

Many of the groups mentioned that they didn't want to feel 'judged' by staff when they sought help related to sex or contraception.

\section{Discussion}

The need for separate services aimed at young people has been long recognised by the Department of Health $(\mathrm{DOH}),{ }^{10}$ and the priority which teenagers give to confidentiality when considering sexual health services is well documented. ${ }^{11-13}$ However, the specific problems encountered by those in rural areas have received less attention and this research has shown that confidentiality is a lesser concern for many young people than the difficulties of conducting private business anonymously in small communities. Whilst targeted services may be a real possibility in populous areas, those resident in small towns, villages and the countryside may be unable to benefit from them. For many teenagers surveyed and spoken to in the course of this research, there were few choices about where they could go for sexual health services. In all cases, these already limited local options are further limited by their concerns about confidentiality and, more particularly, anonymity. These concerns were present in all the FGDs with young people from small towns, both in the girls' groups and the boys' groups. Services which are perceived as more anonymous, such as the main FPC, are difficult to get to because of limited free time and difficulties with transport such as bus times and cost.

Some aspects of confidentiality can be addressed by health professionals. They need to be aware that while young people may sometimes attend a consultation with a parent, they may also visit the doctor independently, especially for sensitive issues such as contraception and sexual health. When parents are present at a consultation, it may be necessary to secure private time with the patients if, for example, questions about the pill or other medication relating to the young persons' sexual activity need to be asked. The same may also be true of other sensitive topics such as smoking or drug use. In addition, doctors need to ensure that computer screens are not visible during consultations.

Teenagers need to be made aware that the duties of confidentiality are designed precisely to prevent medical staff from revealing what is know to them in a professional capacity within personal relationships. Many teenagers spoken to believed that information about them might be casually passed on in social or family situations because of the number of known connections between health professionals and others in their small communities. Health professionals also need to be aware of these fears. More explicit information about the nature of a confidential consultation should be made available to help teenagers understand the scope and limits of confidentiality.

Other aspects of anonymity are more difficult to address. Personal networks in rural areas can be extensive and present a real threat to young people's privacy:

'Heightened visibility can have the effect of denying young people any privacy to conduct their lives and pursue their interests...[this] can create a particularly claustrophobic environment for young people and have repercussions for their ability to gain confidential access to services and advice. ${ }^{14}$

It may be necessary to look at different locations for sexual health services for teenagers in rural areas, which consider their specific needs. Schools already bus young people into a particular location to attend classes. Thus schools provide access to greater numbers of young people than any individual town or village, and may be a more suitable location for a youth-orientated sexual health service. Enhancing the role of the school nurse or placing extended health services, including those for sexual health, with the presence of a doctor, on or close to the school site may be necessary in order to reach rural teenagers who are concerned about being seen at local health services.

\section{Acknowledgements}

The authors would like to thank all the GPs who took part in the survey, Sue Wedge, the pupils who completed questionnaires, and all those who talked so openly and frankly in the focus group discussions.

\section{Statements on funding and competing interests}

Funding. NHS S\&W R\&D Directorate, October 1997-September 2000 Competing interests. None declared.

References

Department of Health. NHS Contraceptive Services, England: 1999-2000. Statistical Bulletin 2000/27 London: Government Statistical Service, 2000.

Exeter FPC. Annual Report 1998-1999. Exeter: Exeter and District Community Healt Service NHS Trust, 1999

Garside R, Ayres R, Owen MR, et al. Drop-in clinics for teenagers in primary care: a controlle trial to determine their acceptability, effectiveness and cost. Working Paper Number 31 Exeter; IPS, 2000

4 Hadley A. Promoting Young People's Sex Advice Centres 'If Only I'd Known', Brook conference, London, 26 November 1997.

Allen I. Family planning and pregnancy counselling projects for young people. London: Gillick $r$ Wishoch

(1985), 3 A11 ER 402 HL.

West J, Hudson F, Levitas R, et al Young people and clinic: Providing for sexual health in Avon: A report to Avon Health Bristol; Department of Sociology, University of Bristol, 1995. Garside R, Ayres R, Owen MR, et al 'They never tell you about the consequences' young

Garside R, Ayres R, Owen MR, et al. General practitioners' attitudes to sexual activity in unde sixteen's. J Roy Soc Med 2000; 93: 1-2.

10 RCOG. Report of the RCOG Working Party on unplanned pregnancies. London: RCOG, 1991. Harden A, Ogden J. Sixteen to nineteen year olds' use of and beliefs about contraceptive services. Br J Fam Plann 1999; 24:141-144.

NHS Centre for Reviews and Dissemination (1997) 'Preventing and reducing the adverse effects of unintended teenage pregnancies'. Effective Health Care 1997; 3(1)

Donovan C, Mellanby AR, Jacobson LD, et al. Teenagers' views on the general practice

: Rural children on a low income. London: The Children's Society, 1997. 